\title{
Aerodynamic Characterization of a Modern Launch Vehicle
}

\author{
Robert M. Hall ${ }^{*}$ and Scott D. Holland ${ }^{\dagger}$ \\ NASA Langley Research Center, Hampton, Virginia 23681 \\ John A. Blevins $*$ \\ NASA Marshall Space Flight Center, Huntsville, Alabama 35812
}

\begin{abstract}
A modern launch vehicle is by necessity an extremely integrated design. The accurate characterization of its aerodynamic characteristics is essential to determine design loads, to design flight control laws, and to establish performance. The NASA Ares Aerodynamics Panel has been responsible for technical planning, execution, and vetting of the aerodynamic characterization of the Ares I vehicle. An aerodynamics team supporting the Panel consists of wind tunnel engineers, computational engineers, database engineers, and other analysts that address topics such as uncertainty quantification. The team resides at three NASA centers: Langley Research Center, Marshall Space Flight Center, and Ames Research Center. The Panel has developed strategies to synergistically combine both the wind tunnel efforts and the computational efforts with the goal of validating the computations. Selected examples highlight key flow physics and, where possible, the fidelity of the comparisons between wind tunnel results and the computations. Lessons learned summarize what has been gleaned during the project and can be useful for other vehicle development projects.
\end{abstract}

\section{Nomenclature}

$\begin{array}{ll}C A F & =\text { axial force coefficient } \\ C L M F & =\text { pitching moment coefficient } \\ C_{l} & =\text { rolling moment coefficient } \\ C_{l_{\beta}} & =\text { coefficient of the derivative of rolling moment with respect to sideslip } \\ C_{l_{\delta a}} & =\text { coefficient of the derivative of rolling moment with respect to rear fin deflection } \\ C N F & =\text { normal force coefficient } \\ C p & =\text { pressure coefficient } \\ \alpha & =\text { angle of attack, degs } \\ \beta & =\text { angle of sideslip, degs }\end{array}$

\section{Introduction}

$\mathrm{T}$ HIS paper is an overview of the efforts to characterize the aerodynamics of the Ares vehicles, which are under development in the Ares Project within the NASA Constellation Program. These vehicles include the Ares I vehicle, which is intended to deliver a crewed capsule to Earth orbit, the Ares I-X, which was the first developmental flight test of the Ares I vehicle, and Ares V, which is a heavy lift vehicle intended to boost other equipment that can be used to deliver the crew and capsule to the Moon and back. Other papers in the sessions of this conference devoted to the Ares project summarize the Ares I-X flight test, ${ }^{1}$ the Ares I database development, ${ }^{2,3}$ details of the experimental ascent flight program, ${ }^{4-8}$ experimental descent program,, 10 computational studies for both the Ares $\mathrm{I}^{11-16}$ and Ares V projects, ${ }^{17-19}$ stage separation simulation,,${ }^{3,5}$ modeling the effectiveness of the roll control system (RoCS) ${ }^{13,15}$ lessons learned concerning uncertainty quantification, ${ }^{20}$ aero-acoustic quantification, ${ }^{21}$ impact of real-gas effects, ${ }^{14}$ plume effects, ${ }^{22}$ testing techniques for launch tower interference, ${ }^{6}$ venting, ${ }^{23}$ flexible vehicle stability, ${ }^{24}$ debris transport, ${ }^{25}$ and other aspects of the development

\footnotetext{
* Ares Aero Panel Chair, Configuration Aerodynamics Branch, Mail Stop 499, Associate Fellow AIAA.

${ }^{\dagger}$ Ares Aero Panel Member, Aero-Thermodynamics Branch, Mail Stop 208, Associate Fellow AIAA.

$\$$ Ares Aero Panel Co-Chair, Aerosciences Branch, Mail Stop EV33, Senior Member AIAA.
} 
project. ${ }^{26-28}$ The current paper gives the general background of the Ares project and includes examples of previous launch programs that experienced pitfalls in characterizing their aerodynamics, summarizes the Ares Aerodynamics Panel, overviews testing and computational strategies, summarizes the workings of both the database team and the uncertainty teams, presents highlights of both the experimental and computational efforts, and lists lessons learned.

\section{Ares Project Background}

Figure 1 compares an early configuration of the Ares I to the Space Shuttle and to Saturn V as well as to a notional drawing of the Ares $\mathrm{V}$ heavy lifter. While the Ares I vehicle is relatively slender for a launch vehicle, the Ares V heavy lifter is similar to the Saturn V vehicle. The mission of Ares I is to deliver the Orion capsule into orbit where it can rendezvous with the Ares V heavy lifter and depart Earth orbit for lunar or other missions.

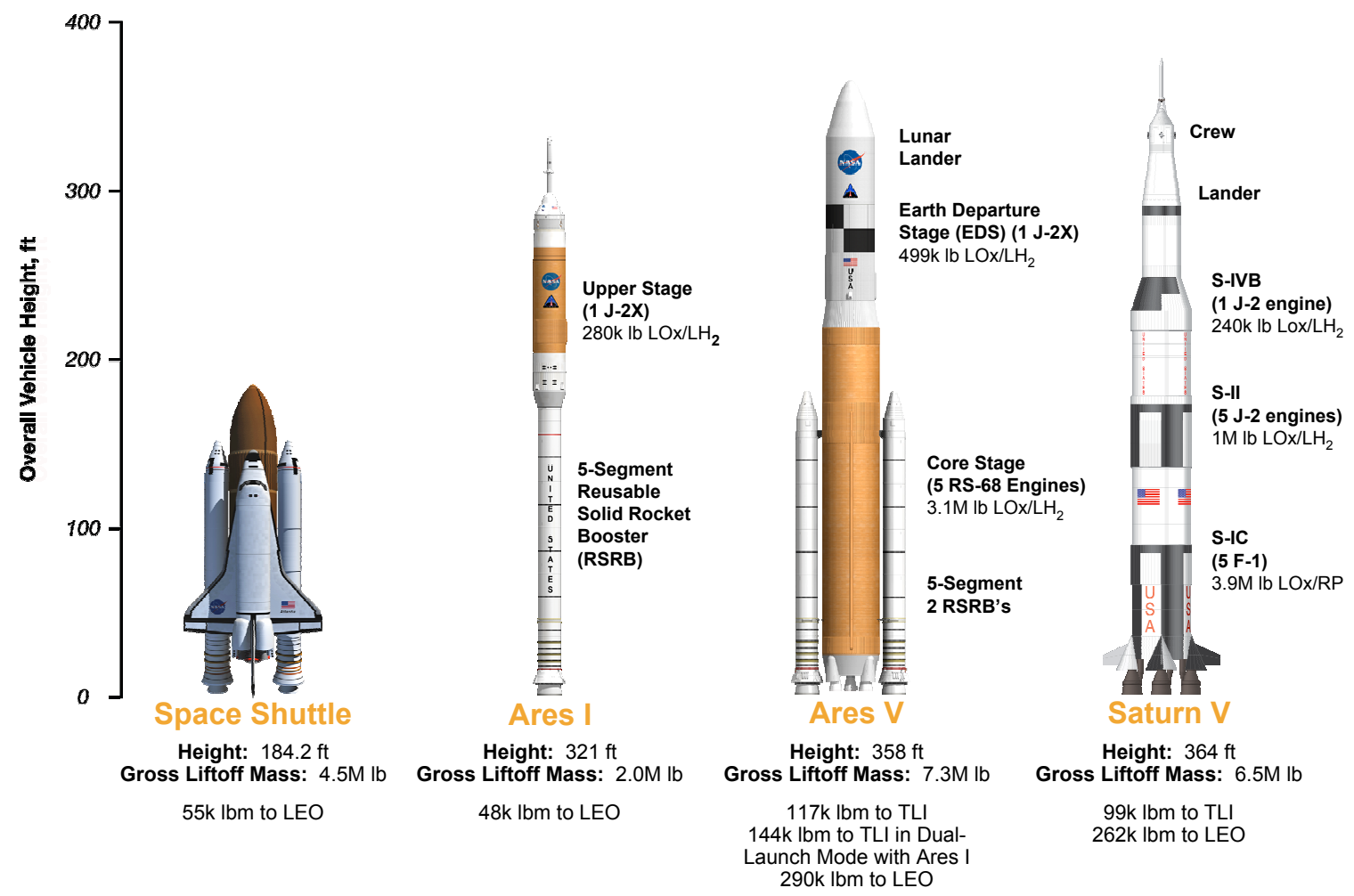

Figure 1. Ares I geometry compared to other launch vehicles.

Figure 2 is a notional drawing of the general layout of an early configuration of the Ares I and shows more details. The Orion capsule is the payload for this launch vehicle and will carry the astronauts for manned missions. A separate Orion Project aerodynamics team is directly responsible for characterizing the Orion capsule. The respective responsibilities of the Ares and Orion Aerodynamics Teams are that the Ares Team is responsible for nominal ascent (no abort scenarios), nominal stage separation, upper stage flight, reentry of the first stage, and reentry of the upper stage. The Orion Team is responsible for the capsule as soon as it separates from the stack until touchdown so Orion must ensure successful aborts, reentries, and touchdowns. Additional information is available on the Constellation Program in the NASA Exploration Systems Mission Directorate (ESMD) Implementation Plan. ${ }^{29}$ 


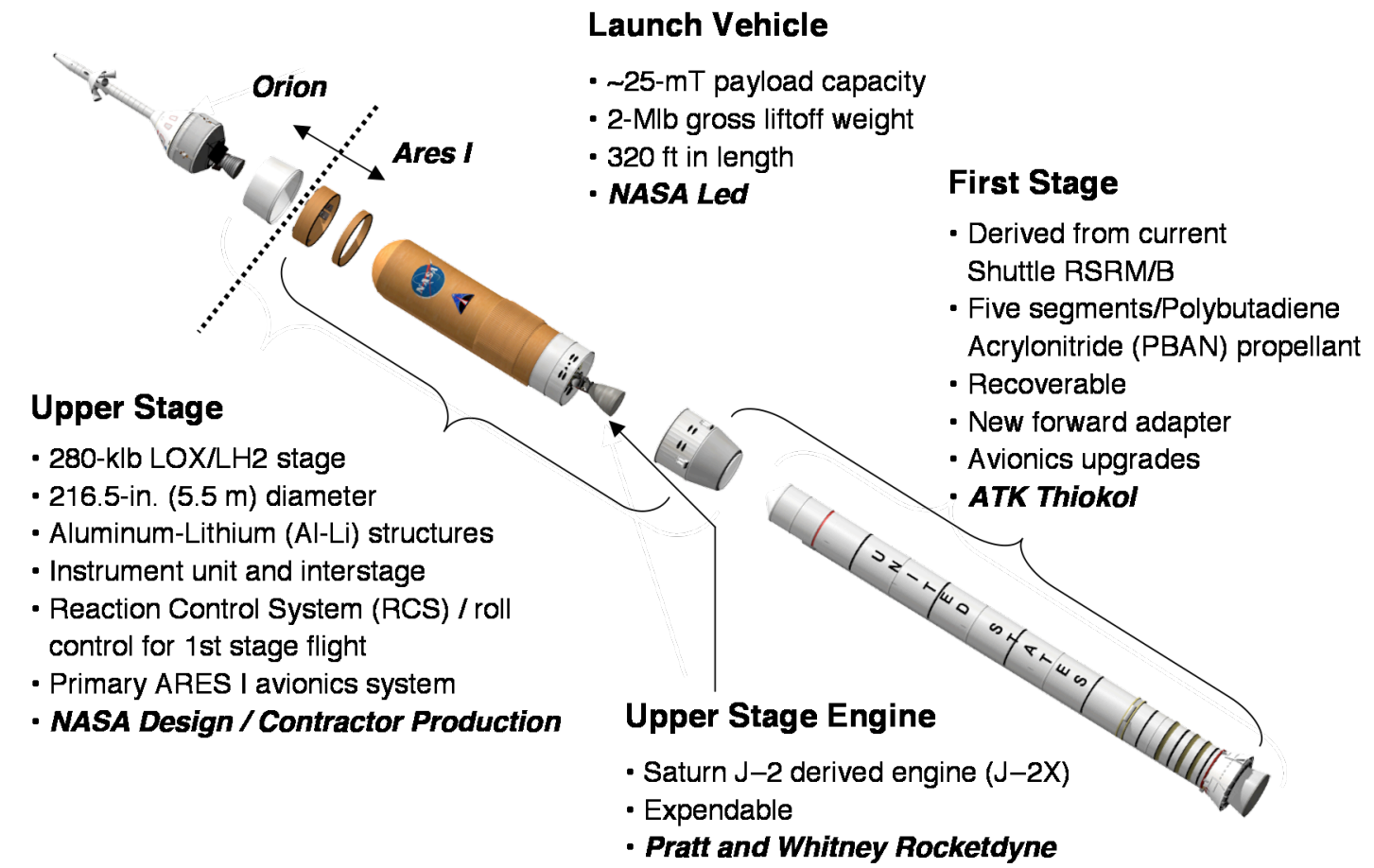

Figure 2. Ares I Elements.

\section{Pitfalls in Characterizing Aerodynamics}

Before discussing what has been done for the Ares aerodynamics characterization, it is useful to illustrate potential pitfalls in developing the aerodynamics of launch vehicles. The first example is for the Pegasus XL launch vehicle, see figure 3. The Pegasus XL was lost during its first launch attempt. Several factors contributed to that loss. First, during development of that vehicle, the complexity of its aerodynamics was underestimated. The vehicle was assumed to be a typical missile while, in fact, it had a significant lifting wing. It was also hoped at the beginning of that program that engineering analysis tools would be sufficient to characterize the vehicle without the need of wind tunnel testing. In addition, the auto pilot design did not provide positive control of sideslip and was not fully evaluated for off-nominal flight. Lessons learned from that flight failure included the need (1) to conduct a standard wind tunnel testing program which would have shown the errors in the originally predicted aerodynamics, (2) for an improved autopilot which would blend "skid and bank-to-turn" characteristics, (3) for a more accurate method for estimating sideslip, and (4) for improved filtering to prevent structural bending modes from corrupting vehicle rate and acceleration signals. A specific example of the shortcomings of the original dataset is shown in the graph in figure 3, which shows that for the standard length Pegasus vehicle, labeled Std in the figure, the level of roll stability, $\mathrm{C}_{\mathrm{l}_{\beta}}$, was approximately twice what was predicted. However, that factor of two mismatch became a factor of nearly 4 for the XL configuration. That larger factor proved to be too large for the control laws and led to the loss of the vehicle. 

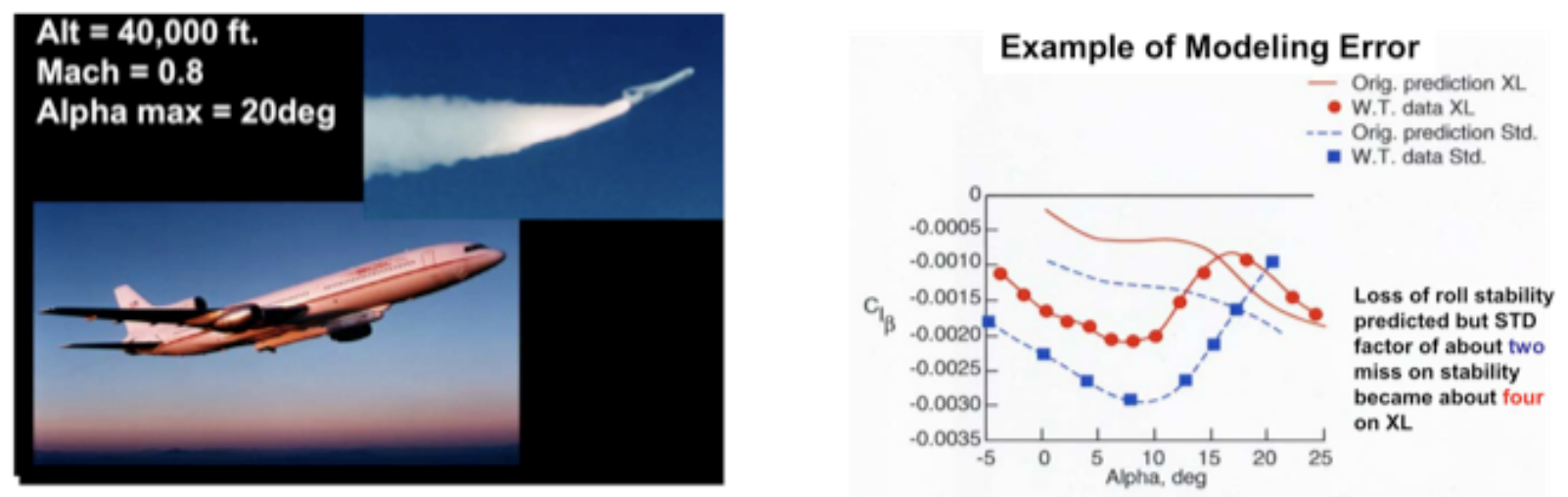

Figure 3. Pegasus XL loss of vehicle example.

The next example also comes from the Pegasus XL launch system during its first attempt to launch the NASA X-43 Hyper-X, see figure 4. In trying to keep costs under control, the wind tunnel testing program for this effort was very compressed. In creating the database, an error was made in that the rear fin effectiveness was estimated using only one rear fin deflection, $\delta a$, and then assuming that the model was symmetric. Unfortunately, the model was not symmetric and so the actual fin effectiveness, $\mathrm{C}_{\mathrm{l}_{\delta \mathrm{a}}}$, was higher than believed by 15 to 25 percent. In addition, after the wind tunnel testing was completed, it was decided to add TPS to the fin leading edges, which had the unintended consequence of increasing the rear fin effectiveness an additional 3 to 8 percent. This all resulted in more control authority than expected and unsteady oscillations. This coupled with nonlinear hinge moments on the vehicle aft fins, which were not seen due to coarseness in deflections evaluated, resulted in the failure of the fins and the loss of the vehicle.

\section{Example of Modeling Error}
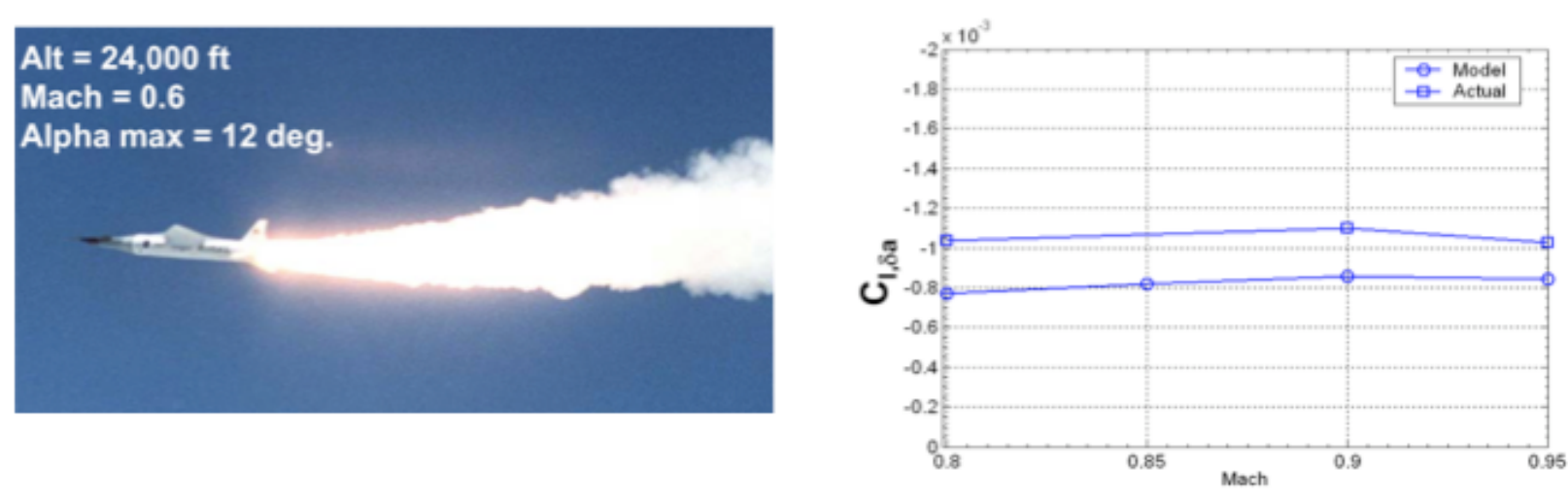

Figure 4. Pegasus XL loss of vehicle example.

The last example, see figure 5, was the result of an unsteady flow problem involving the Delta II Heavy launch vehicle. In this case, the Boeing Company had followed standard industry best practices in wind tunnel testing but failed to identify the presence of flow unsteadiness, which is not readily apparent with "best practices." This launch vehicle uses larger strap-on rocket boosters than the standard Delta II launch vehicle and had experienced some larger than expected main engine gimballing during its first two flights. After some adjustments to its flight control, a third flight, the Messenger flight, was launched. However, post-flight analysis of that third flight revealed that the gimballing issue was worse than on its first two flights. Realizing that the root cause of the problem was not understood, Boeing and Kennedy Spaceflight Center (KSC) approached Langley Research Center (LaRC) to help them understand the mechanism responsible for the unexpected moments on the vehicle. By taking time histories of both the wind tunnel balance and unsteady pressure transducers, it was found that unsteady separation was occurring under the solid rocket boosters and that this was 
the physical process that was impacting the moments on the vehicles and resulting in the larger-than-expected gimballing of the main engine. Because of the cooperative work between NASA and Boeing, Boeing engineers were able to predict the upper bounds of the possible unsteady moment, modify their flight control laws again, and successfully resume launch activities.

\section{Challenge \\ Delta II Heavy: main engine deflections in transonic flow regime higher than predictions}

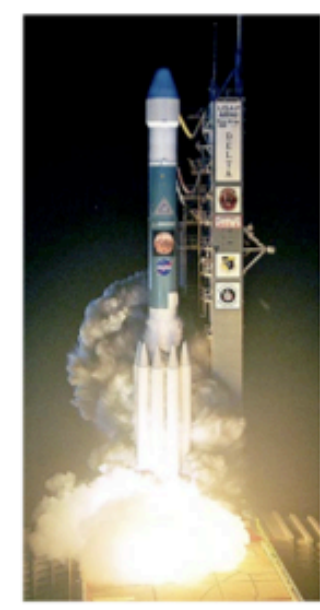

\section{NASA and Company Response}
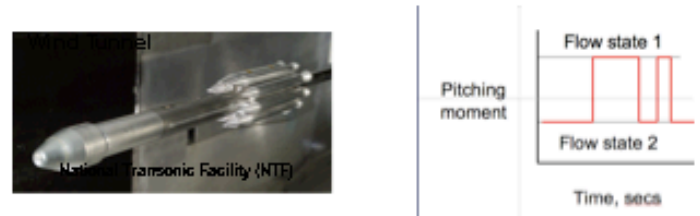

NTF identifies multistate nature of pitching moment over 60 secs at constant tunnel conditions
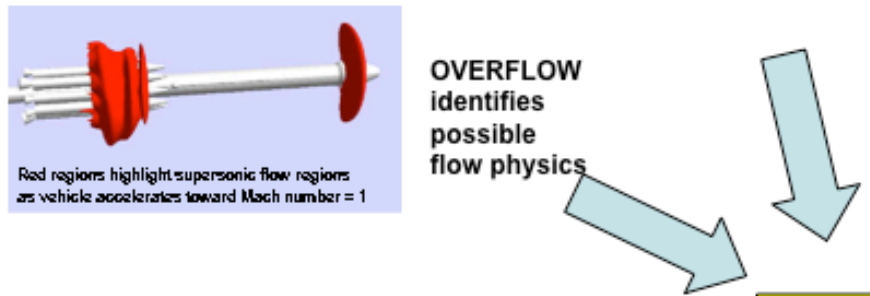

Langley flight dynamics and control analysis experts work with company engineers to assess data used by flight simulation and control laws

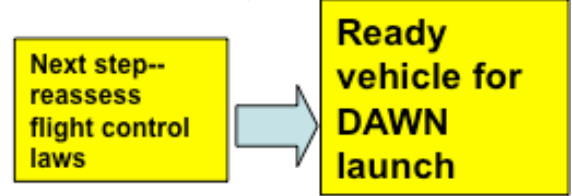

Main engine deflections larger than predicted based on winds aloft for all 3 previous successful flights--MER-B, SIRTF, and MESSENGER

Figure 5. Delta II Heavy example of finding unsteadiness issues in flight.

The bottom line is that developing the aerodynamic characteristics of a launch vehicle can be difficult and the risk grows as less wind tunnel testing is employed. Even when employing a best practices wind tunnel effort, problems can still arise.

\section{The Aerodynamics Panel}

The Ares Project, which involves a number of NASA centers, relies on a series of technical discipline panels as well as "elements" that represent teams for each part of the vehicle itself, such as First Stage, Upper Stage, J$2 \mathrm{X}$ engine, etc. The Aerodynamics Panel is the appropriate discipline panel for the aerodynamics of the Ares vehicles. As shown in figure 6, the Aerodynamics Panel interacts with Guidance, Navigation, and Control (GN\&C), the Ascent Performance Panel, the Loads and Structural Dynamics Panel, and the Thermal Environments Panel. Other interactions include those with the Orion Aerodynamics Team, which is responsible for the Orion capsule once it separates from the launch stack, as well as the Ares I-X Project aerodynamics team. A broader aerodynamics team of engineers and researchers support the Aerodynamics Panel and consist of NASA employees residing at the Langley Research Center, Marshall Space Flight Center (MSFC), and the Ames Research Center. 


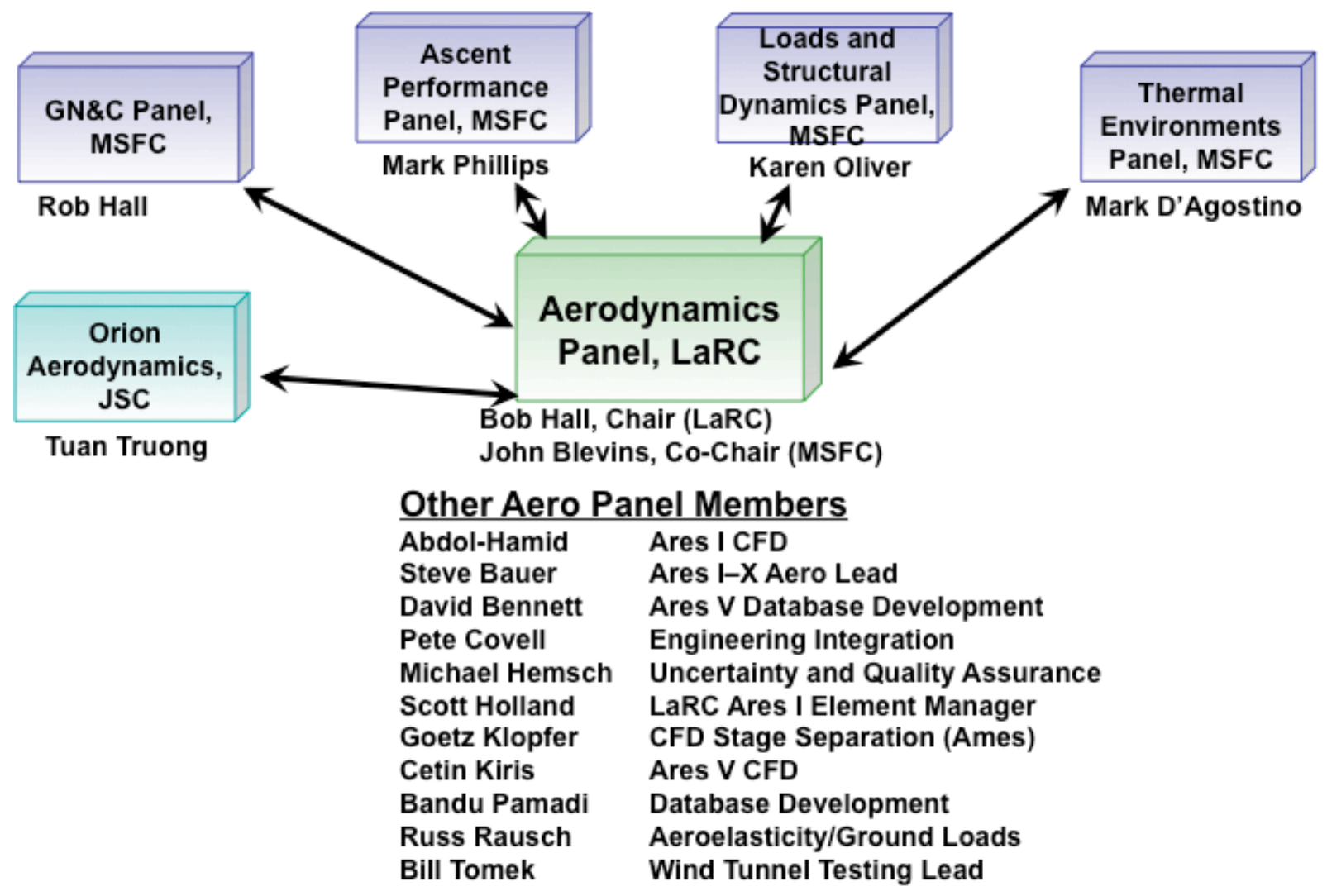

Figure 6. Ares Aerodynamics Panel and its primary interactions.

The Aerodynamics Panel is responsible for directing the aerodynamics testing and analysis and for the quality and correctness of the aerodynamic data being shared across the Ares project.

\section{Strategies for Wind Tunnel Testing and Computations}

During the development of both the Saturn V and the Space Shuttle system, wind tunnel testing had to provide the bulk of the data for database development. Full Navier-Stokes computations were much less mature and computational resources did not exist nearly to the extent that they do presently. Conversely, doing extensive testing in multiple wind tunnels, as was done on the earlier programs, is not as practical today with increased costs of testing and reduced availability of facilities. Consequently, computational fluid dynamics (CFD) is appropriately expected to play a much larger role today than in any legacy, crewed program.

Whether using CFD or the wind tunnels, planned redundancy is built into the data generation when possible. For example, two different tunnels are typically used to gather data in the subsonic to low supersonic data range and in the supersonic data range. Therefore, an important feature of the program is to make sure that there is overlap in data between the two facilities. Similarly, employing multiple codes was a crucial step in determining best practices. Initially, as many as three codes were used to ensure that nothing was amiss between the different solvers, the gridding strategies, or in the choices of turbulence models. Then, after consistency checks served their purpose, best practice evolved into using a second code to check a limited number of the computations of the primary code. Finally, CFD is only as good as its turbulence modeling and gridding, so the wind tunnel and flight test, when available, play a crucial role in providing data to the code users to help them establish best practices, such as grid densities requirements and applicability of different turbulence models.

For the current program, wind tunnel testing is the major provider of forces and moments for database development. While the up-front expenses of conducting a wind tunnel test are large, the wind tunnel is a very efficient means of measuring a vehicle's aerodynamic characteristics for a large number of configurations or conditions, such as Mach number, angle of attack, and angle of sideslip. On the other hand, CFD can address issues that are difficult to address in the wind tunnel. For example, CFD solutions contain a complete description 
of surface pressures and the forces and moments on protuberances. While wind tunnel models without protuberances can take advantage of symmetry about the body axis by rotating a line of pressure taps to determine surface pressures distribution, this is no longer the case once protuberances are added and symmetry about the body axis is lost. Even for a very large model 12 or more feet long, it would be difficult to have enough pressure ports to integrate to high accuracy the sectional normal force or localized loads on the protuberances themselves.

Nearly all wind tunnels suffer from a lack of Reynolds number capability when compared to flight with a few exceptions like the National Transonic Facility (NTF) at LaRC. For the Ares vehicles, even the high Reynolds number capability of the NTF is not sufficient to reach flight Reynolds numbers in the transonic region. Consequently, CFD contributes in a unique manner to quantify increments in Reynolds number between the usual force and moment testing at conventional wind tunnel Reynolds numbers and those of flight.

\section{Database Development and Uncertainty Quantification}

Having wind tunnel or CFD data available is only the first step in providing a database to the customers of aerodynamics. Usually, the data must be put into a form that is easy for the customer to use and includes, in many cases, additional manipulation of the wind tunnel data. For example, a database may combine a wind tunnel data set with CFD predicted increments, such as those due to Reynolds numbers. All these steps to generate the database are carried out by the database team, which is a key component of the broader aerodynamics team.

Uncertainty quantification is another demanding job. At the most basic level, the uncertainty team must be able to quantitatively describe the uncertainty within the wind tunnel database or for the CFD solutions. However, while this is the basic requirement, the full requirements are driven by the customers who need to have uncertainties large enough to envelope the nominal values on flight day. That is, the uncertainty today needs to encompass potential migration of the nominal values in going from wind tunnel data to the actual flight vehicle. Before going to critical design review, most of these impacts will be evaluated and increments determined, but the uncertainty team must estimate a current level of uncertainty that will be large enough to bound all of these future potential impacts.

\section{Wind Tunnel Highlights}

An example of unsteady flow is that of the naturally occurring unsteadiness near the sonic conditions within the wind tunnel. This example is taken from testing of a rigid buffet model of the Ares I-X flight test vehicle in the Transonic Dynamics Tunnel at Langley (figure 7). Figure 8 shows a static image of the oscillating shocks just aft of the base of the capsule.

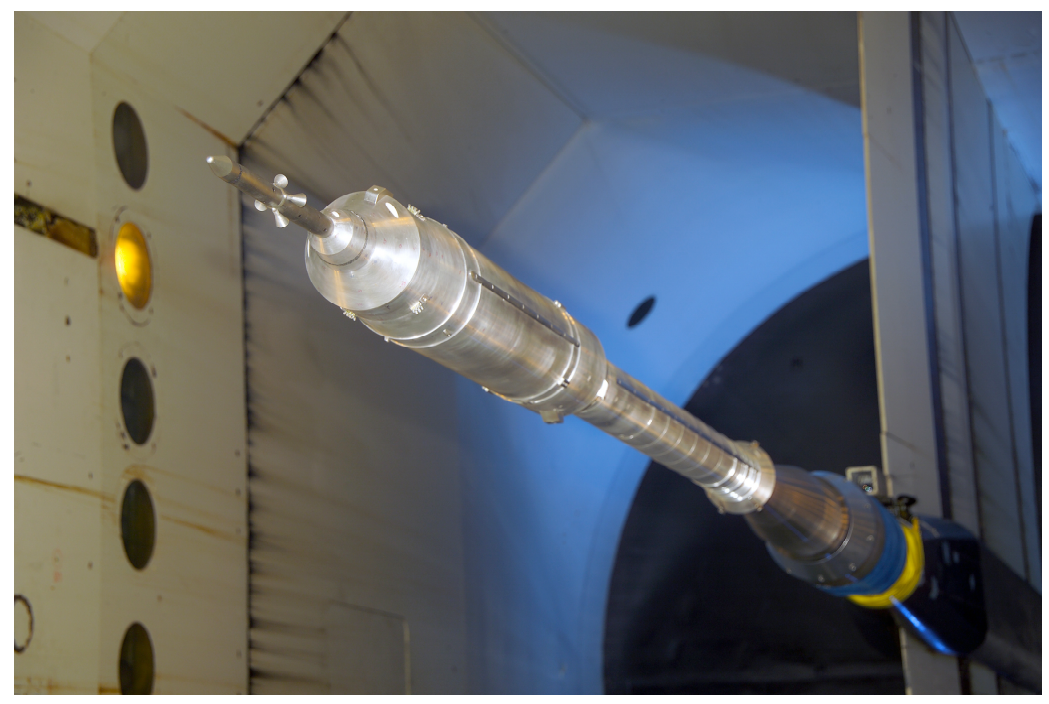

Figure 7. 3.5 Percent Ares I-X model in the Transonic Dynamics Tunnel at Langley. 


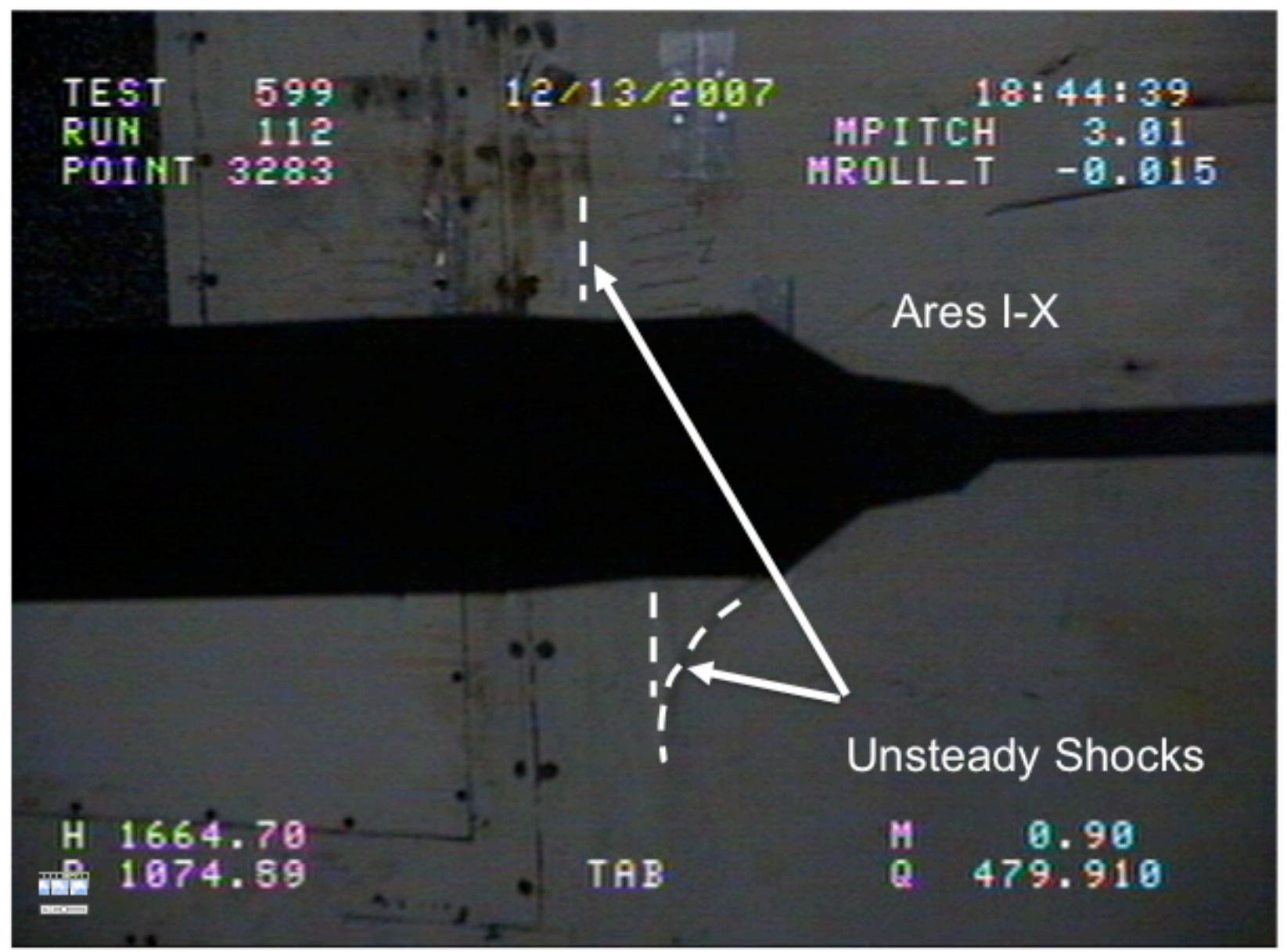

Figure 8. Unsteady shocks found during test of 3.5 percent Ares I-X model in the Transonic Dynamics Tunnel at Langley. Mach $=0.90, \alpha=3^{\circ}$.

A second wind tunnel highlight is from a test in the LaRC 14- by 22-Ft Tunnel simulating the Ares I lifting off of the pad in the presence of a service tower. This experiment was intended to evaluate tower-interference testing in this facility to determine if it compared well to the usual, higher-fidelity tower-interference testing in the Transonic Dynamics Tunnel (TDT). Figure 9 illustrates wind tunnel installations in both the TDT and the 14- by 22-Ft facilities. The TDT testing, as mentioned, is the usual, high fidelity test for tower interference since the facility can test a very large-scale model with its 16-ft tunnel height. It also operates with heavy gas to give higher Reynolds number capability. The 14- by $22-\mathrm{ft}$ test not only evaluated tower interference coefficients but also assessed them with the vehicle at various heights above the launch platform to address tower clearance issues (see images in the lower right of figure 9). In addition, the 14- by 22-ft test was also used to evaluate the Ares I vehicle from low to high alpha conditions out of the presence of the tower. 


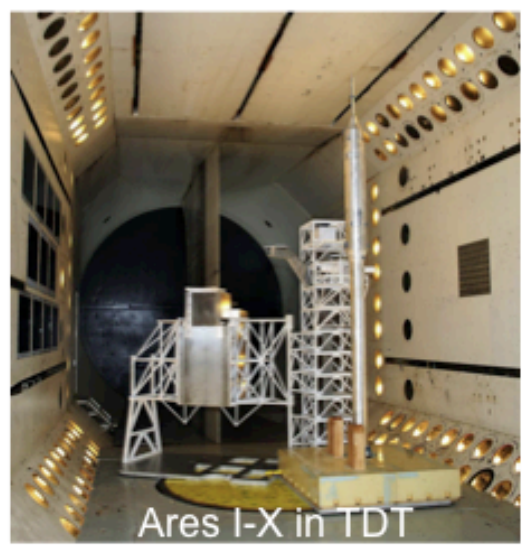

Langley Transonic Dynamics Tunnel

- 16 -ft square test section, used $4.05 \%$ scale model

- $0.1 \leq$ Mach $\leq 0.28$

- Heavy gas gives higher Reynolds numbers

\section{Langley 14- x 22-ft Subsonic Tunnel}

- Ares tested $1.75 \%$ scale model

- $0.1 \leq$ Mach $\leq 0.3$

- Air medium results in lower Reynolds numbers

- Without tower, able to test for $0^{\circ} \leq$ alpha $\leq 90^{\circ}$

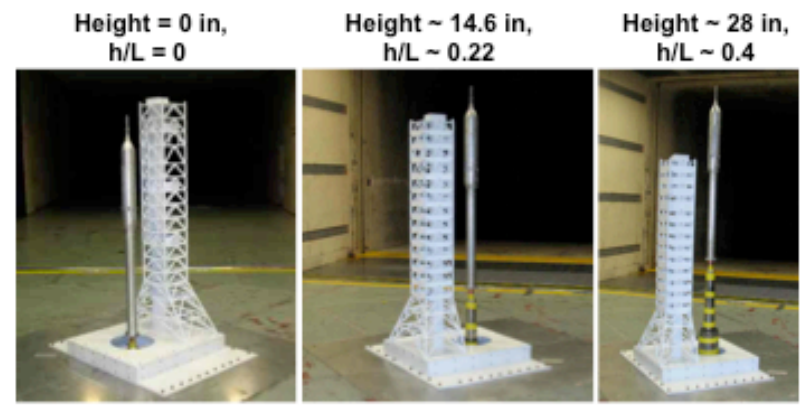

Ares I in 14- by $22-\mathrm{ft}$

Figure 9. Tower inference testing.

A third highlight is for the First Stage re-entry characterization conducted in the MSFC 14-inch Aerodynamic Research Facility. First Stage re-entry characterization provides simulation personnel with the data with which to compute the probability that First Stage will or will not be successfully recovered by its parachute system. The success of that recovery has been considered very crucial during the Space Shuttle program to be able to monitor the performance of the seals between the motor segments of the solid rocket boosters. For Ares I, the same level of scrutiny is expected and so it was very important for the project to characterize the aerodynamics of the First Stage descent configuration over a large Mach number and angle of attack range. A picture of the 14-inch tunnel is shown in figure 10 as well as a close-up of the First Stage descent configuration.

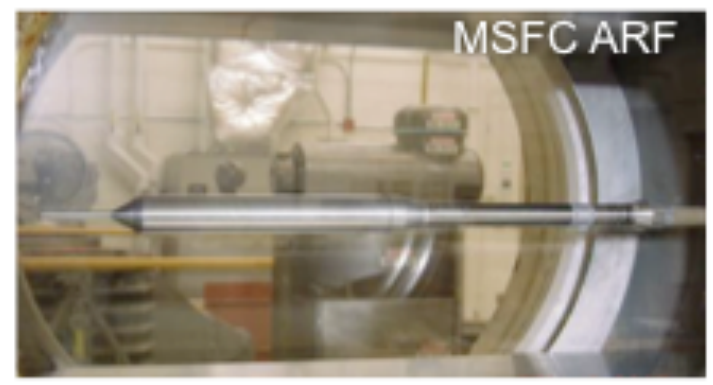

Early Ares Model in 14-in Aerodynamic Research Facility

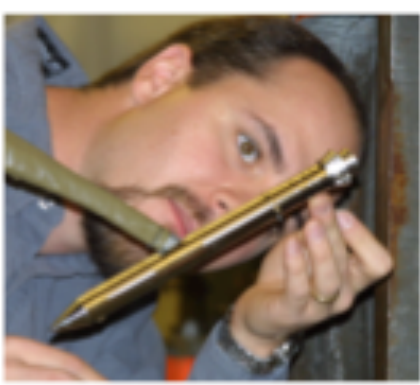

\section{Engineer with $1^{\text {st }}$ Stage} Descent Model

Figure 10. First Stage descent testing in the Marshall Space Flight Center 14-inch tunnel. 


\section{CFD Highlights}

The highlights from the CFD team include examples of agreement between the wind tunnel testing and CFD for forces and moments and line load information for Ares I, an example of a stage separation simulation for Ares I, and several examples of Ares V simulations. While not discussed, local pressures for venting analyses are also provided by CFD.

Figure 11 shows an example of the level of agreement between the CFD and the database, which is heavily weighted to the wind tunnel values for forces and moments taken in the Langley Unitary Plan Wind Tunnel and in the Boeing Polysonic Wind Tunnel. The CFD values are from the primary ascent aerodynamics code, USM3D. In general, the code underpredicts axial force coefficient for supersonic Mach numbers but does a good job with normal force and pitching moment coefficients. Other papers presented in this session will give more details of the Ares I computations. ${ }^{11-16}$
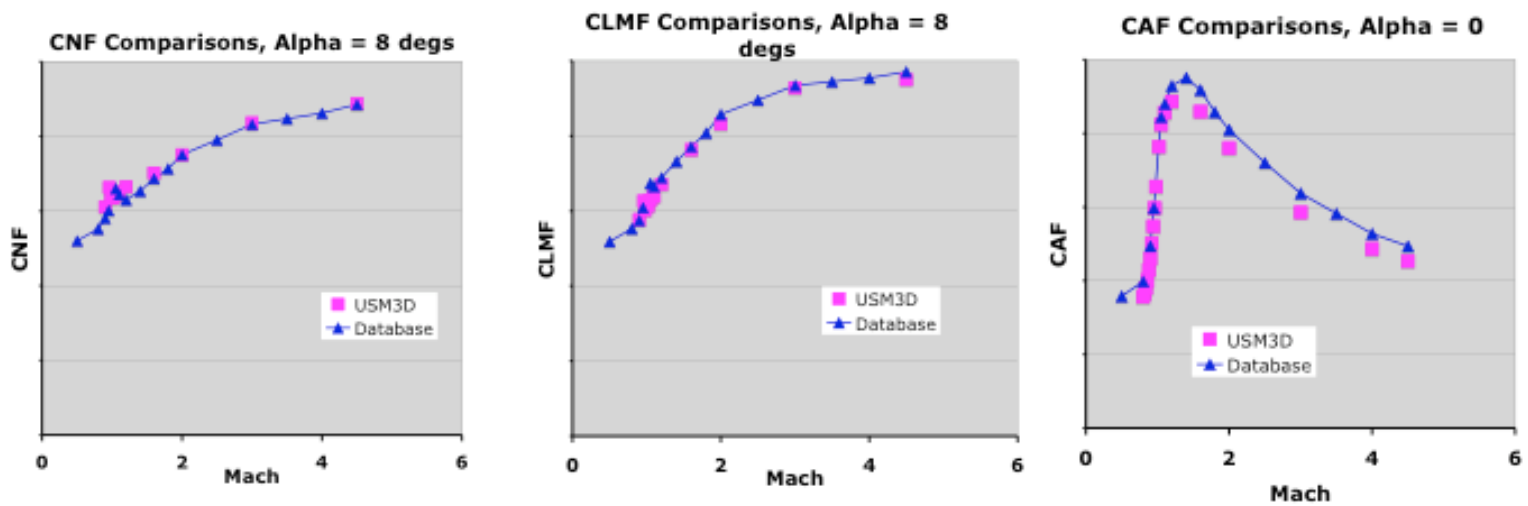

Figure 11. Agreement between CFD and A106 configuration with BDMs aft.

The first step in validating the CFD line loads is to compare the solutions and wind tunnel results for the case of protuberances off. This first step is necessary due to experimental limitations in determining pressures around the wind tunnel model. The wind tunnel model is designed to have a primary pressure row down the length of the model that can be rotated around the body axis to map the entire surface pressures about the model, even when the vehicle is at an angle of attack for the case of no protuberances. This pressure map is then integrated to give experimental sectional normal or axial forces that can be compared to the CFD predictions. Of course, when the protuberances are added, all symmetry about the body axis is lost, and the single pressure row down the model cannot be used to map out the pressure field over the entire vehicle. Figure 12 compares the experimentally determined sectional normal force to that predicted by the computations for the case of no protuberances.

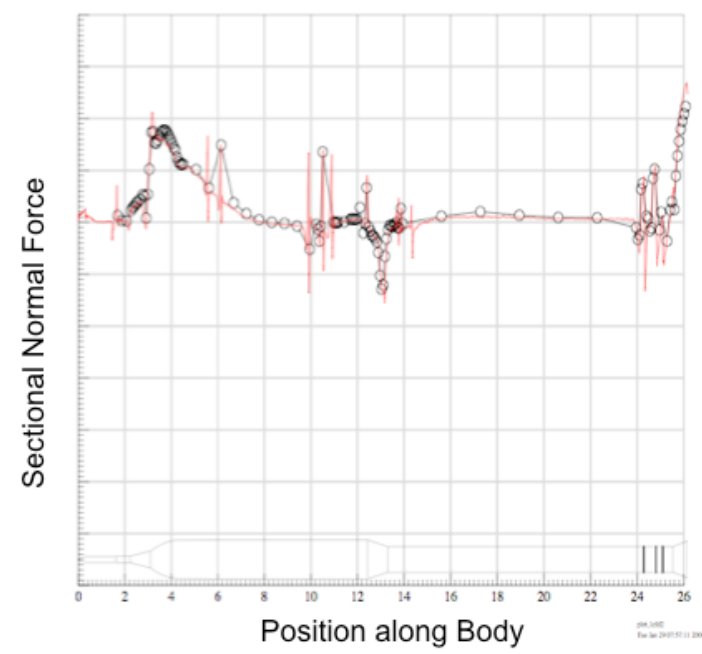

Figure 12. Sectional normal force without vehicle protuberances compared between CFD (red line) and wind tunnel (black circles).

10

American Institute of Aeronautics and Astronautics 
A significant effort of the Ares CFD team has gone into stage separation simulation for Ares I. This effort computes the forces and moments on the upper stage and the First stage as the two stages begin to separate from each other. The CFD simulation is very complex and involves separating stages, ten booster deceleration motors (BDMs) firing, and four ullage settling motors (USMs) firing. This CFD effort has been headed by Goetz Klopfer of Ames. A full paper on this subject will not be presented in the present sessions but an image of the flow field is shown in figure 13. Although results illustrate the type of detailed flow field information available from CFD, powered CFD results were not validated against wind tunnel experiment under the Ares program due to resource, technical, and schedule constraints.

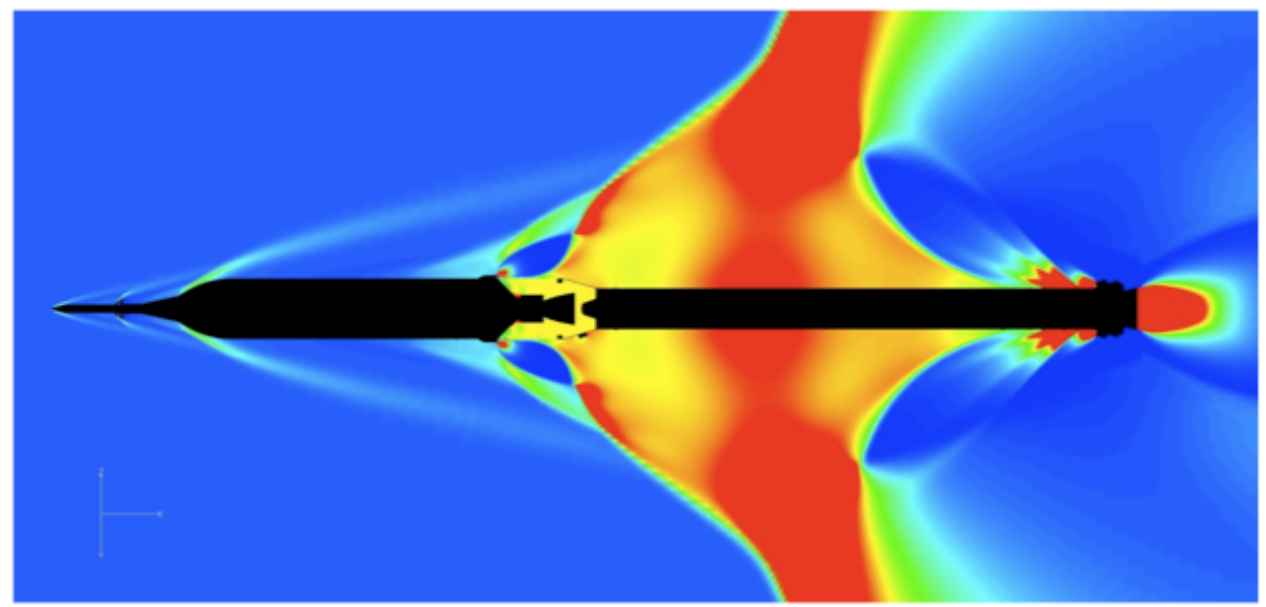

Figure 13. Complex flow field interactions due to BDMs and USMs firing. Pressures vary from low values (blue) to high values (red). Solution from Goetz Klopfer using OVERFLOW.

The Ares $\mathrm{V}$ heavy lift configuration has also been studied using both the 14-inch ARF at MSFC as well as with CFD at both Ames and LaRC. The vehicle is still in its early development cycle but its early OMLs have been analyzed using both an Euler solver, Cart3D, as well as two viscous codes, OVERFLOW and USM3D. CFD databases for Ares $\mathrm{V}$ have been generated quickly using NASA's modern supercomputing facilities at Ames. These CFD simulations have been corroborated by experimental wind tunnel data and have extended predictions to flight Reynolds numbers. Simulations so far have predicted forces and moments, line loads, plume effects, plume-induced flow separation, as well as solid rocket booster (SRB) separation. Sample computations illustrating the flow field as a function of Mach number are shown in figure 14 and this topic area will be discussed more fully later in this conference. ${ }^{17,18}$ An example of a stage separation computation for Ares V is shown in figure 15.

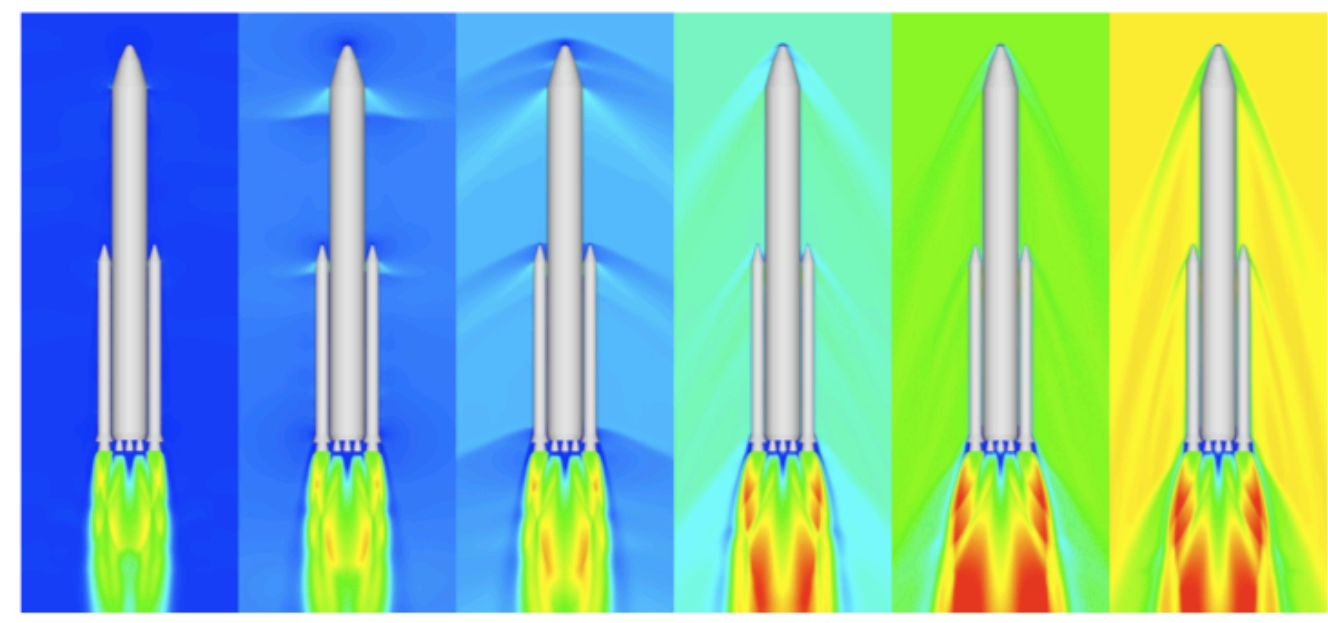

Increasing Mach numbers from left to right

Figure 14. Increasing Mach number impacts to flow field. Solution by Cetin Kiris using OVERFLOW. 


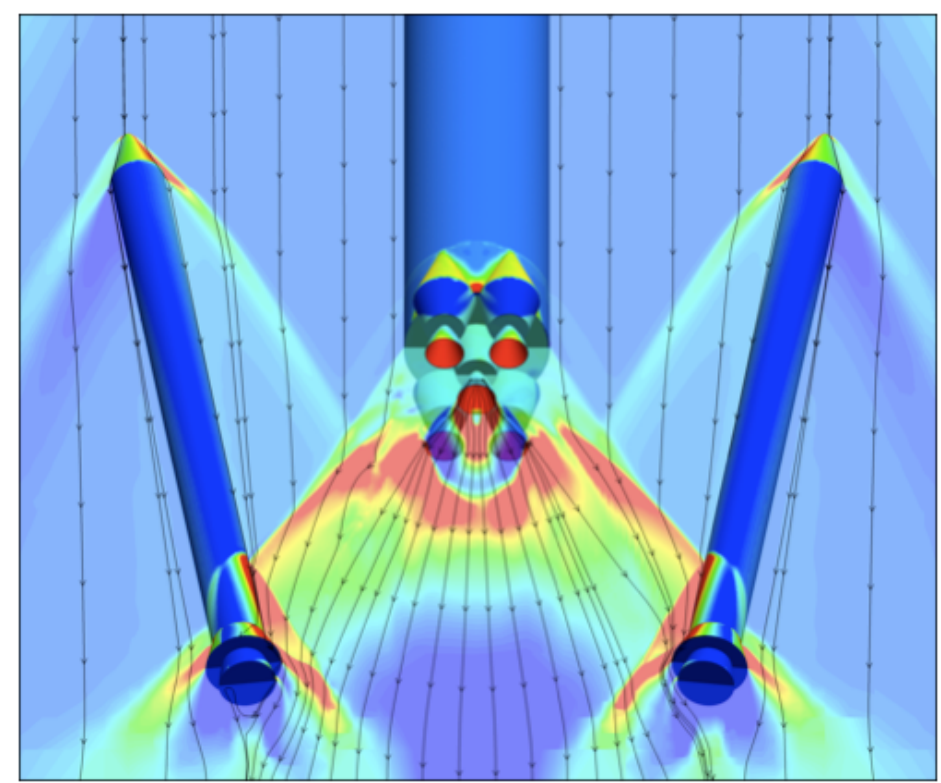

Figure 15. Example stage separation computation for Ares V. Solution by Cetin Kiris using Cart3D.

CFD has also been critical in predicting exhaust plume effects for the main engine, the RoCS, the BDMs, and the USMs. As of this point in the project, independent validation of any plume interactions has not been conducted in the wind tunnels and remains somewhat of an open issue. However, flight data addressing the RoCS plume interactions were attained during the flight of the Ares I-X vehicle during October of 2009, see figure 16. As seen in the plot of that figure, the predictions of "knockdowns" due to originally predicted detrimental jet interactions (JI) with the RoCS firing were too conservative, see the peak between Mach $=0.7$ and 1.0. Thus, flight vehicle data gave practical insight into the RoCS jet interactions and is resulting in improved CFD best practices. ${ }^{1}$

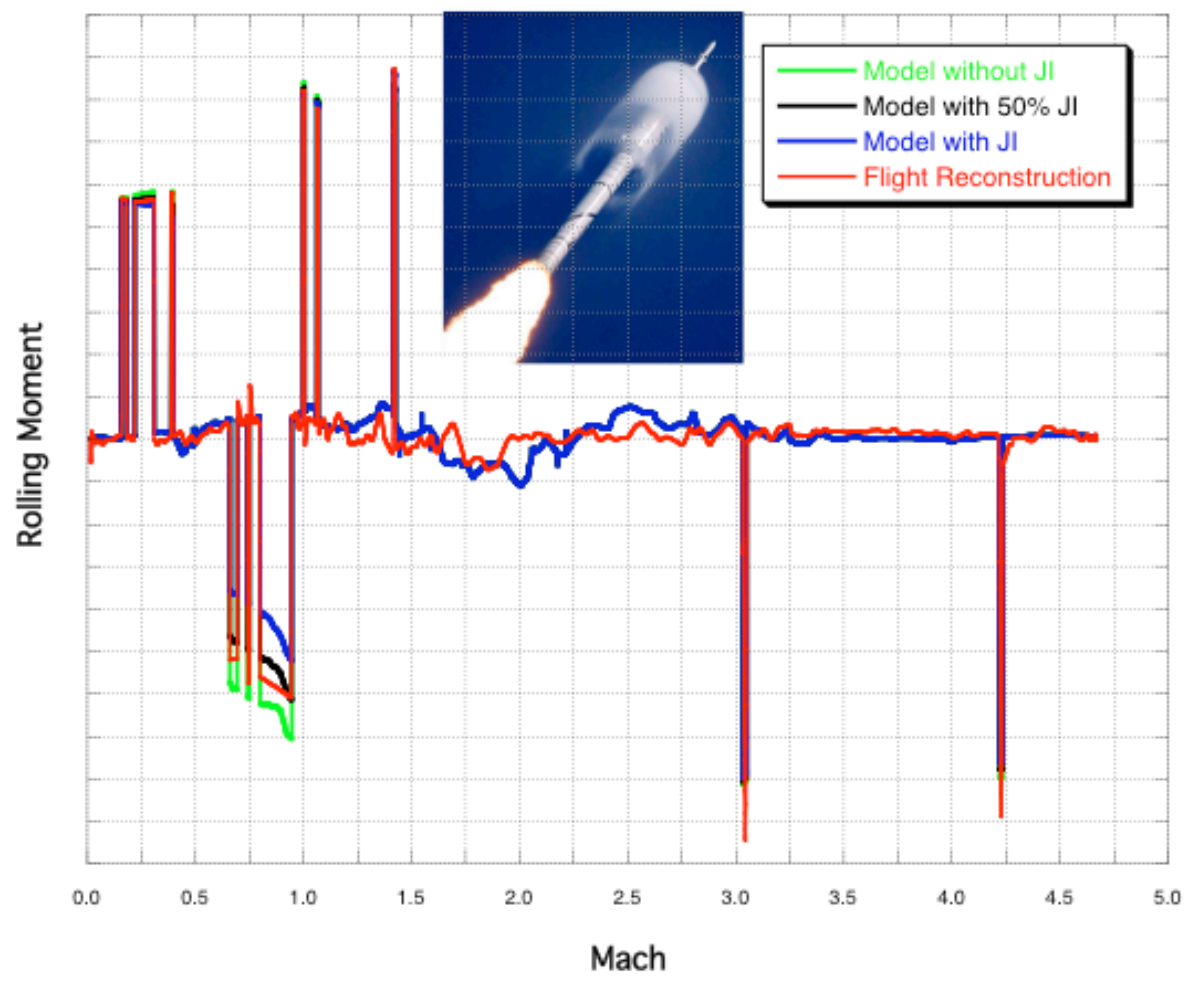

Figure 16. Ares I-X flight test sheds light on CFD best practices.

12

American Institute of Aeronautics and Astronautics 


\section{Lessons Learned}

Based on the past 5 years of development of the aerodynamic databases, a number of lessons learned can be summarized.

1. Integration and checking between the Aerodynamics Panel and its customers is a continual and necessary effort to make sure that the appropriate requirements are met in a timely fashion at the various stages of the project and that the customers implement that information in the manner intended.

2. Analysis and understanding of both wind tunnel and computational data is essential if bad data are to be identified before being placed into a database. A project must have enough personnel in order to have cross checking to make sure that mistakes or best practice shortcomings are identified.

3. When there is, for example, a lack of validation of the key CFD data, this shortcoming should be entered into a risk tracking system so that the stakeholders are aware of the shortcoming.

4. Experimental simulation of the plumes is extremely difficult and costly. The Ares I project never executed a validation of RoCS plume-on effects because of the technical difficulty of the experimental effort with such a slender vehicle. Recent comparisons with flight have triggered a re-examination of computational best practices. A wind tunnel validation experiment of RoCS plumes is a very high priority if the Ares I project continues.

5. Stage separation is another high-risk endeavor that is extremely difficult to execute in the wind tunnel. Getting the correct mass flow ratios between the booster separation motors plumes and the freestream is extremely challenging. Again, the result is reliance on the CFD solutions, which have no direct validation. Flight test is the ultimate test to establish the truth data.

\section{Summary}

The Aerodynamics Panel with the help of the entire aerodynamics team is executing a highly integrated $\mathrm{CFD} /$ wind tunnel program to characterize the aerodynamics of the Ares vehicles. The wind tunnel is generally used to generate the force and moment databases provided to the Ascent Performance and to the GN\&C disciplines while CFD is used to generate the line loads and local pressure distributions for the vehicle. Routinely, the CFD computations are completed before the wind tunnel entry so that the CFD is being used in a predictive mode and can reevaluate its best practices only after comparisons to the wind tunnel data are completed. The line loads and associated pressures are used by the project elements responsible for their respective part of the flight vehicle to incorporate venting and to analyze loads on specific components. The Aerodynamics Panel and the broader team are composed of engineers from Ames, Marshall, and Langley, making communication and coordination necessary keys to the successful operation of this team. The major purposes of the Aerodynamics Panel is to ensure that lessons learned and best practices are communicated across the aerodynamics team and that all relevant aerodynamics data are reviewed and vetted.

\section{References}

${ }^{1}$ Bauer, S. X., Krist, S. E., and Compton, W. B., "Generation of the Ares I-X Flight Test Vehicle Aerodynamic Data Book and Comparison to Flight," AIAA Paper No 2011-0XXX, January, 2011.

${ }^{2}$ Pamadi, B. N., Pei, J., Covell, P. F., Favaregh, N. M., and Gumbert, C. R., "Aerodynamic Analyses and Database Development for Lift-Off, Transition, and First Stage Ascent of the Ares I A106 Vehicle," AIAA Paper No 2011-0XXX, January, 2011.

${ }^{3}$ Pamadi, B. N., Pei, J., Pinier, J. T., Klopfer, G., and Holland, S. D., “Aerodynamic Analyses and Database Development for Ares I Vehicle First Stage Separation,” AIAA Paper No 2011-0XXX, January, 2011.

${ }^{4}$ Tomek, W. G, Erickson, G. E., Hanke, J. L., and Pinier, J. T., "Overview of Experimental Investigations for Ares I Launch Vehicle Development," AIAA Paper No 2011-0XXX, January, 2011.

${ }^{5}$ Pinier, J. T., and Niskey, C. J., “Ares I and Ares I-X Stage Separation Aerodynamic Testing,” AIAA Paper No 20110XXX, January, 2011.

${ }^{6}$ Capone, F. J., Paulson, J. W., and Erickson, G. E., "Liftoff and Transition Aerodynamics of the Ares I (A106) Launch Vehicle," AIAA Paper No 2011-0XXX, January, 2011.

${ }^{7}$ Pinier, J. T., Niskey, C. J., Hanke, J. L., and Tomek, W. G., “Ares I Aerodynamic Testing at the Boeing Polysonic Wind Tunnel," AIAA Paper No 2011-0XXX, January, 2011. 
${ }^{8}$ Erickson, G. E., and Wilcox, F. J., "Ares I Aerodynamic Testing at the NASA Langley Unitary Plan Wind Tunnel," AIAA Paper No 2011-0XXX, January, 2011.

${ }^{9}$ Blevins, J. A., Pritchett, V. E., Haynes, D., Purinton, D. C., and Carpenter, M. A., "Ares I First Stage Reentry Aerodynamics Database Development and Trajectory Modeling," AIAA Paper No 2011-0XXX, January, 2011.

${ }^{10}$ Blevins, J. A., Pritchett, V. E., Crosby, W. A., "Reynolds Number Effects of Cylinders at High Angles of Attack at Transonic and Supersonic Mach Numbers," AIAA Paper No 2011-0XXX, January, 2011.

${ }^{11}$ Abdol-Hamid, K. S., Ghaffari, F., and Parlette, E. B., "An Overview of Ares I CFD Ascent Aerodynamic Data Development and Analysis Based on USM3D," AIAA Paper No 2011-0XXX, January, 2011.

${ }^{12}$ Kless, J., Lee, H. C., Klopfer, G. H., and Onufer, J. T., "Validation of OVERFLOW for Computing Plume Effects During the Ares I Stage Separation Process," AIAA Paper No 2011-0XXX, January, 2011.

${ }^{13}$ Deere, K. A., Pao, S. P., and Adol-Hamid, K. S., "Computational Analyses of Ares I Roll Control System Jet Interactions (on Rolling Moment)," AIAA Paper No 2011-0XXX, January, 2011.

${ }^{14}$ Hall, L. H., Eppard, W. M., and Applebaum, M. P., "Multi-Species Effects for Plume Modeling on Launch Vehicle Systems," AIAA Paper No 2011-0XXX, January, 2011.

${ }^{15}$ Pao, S. P., Deere, K. A., Abdol-Hamid, K. S., "Establishing Approaches to Modeling the Ares I-X and Ares I Roll Control System with Free-Stream Interaction,” AIAA Paper No 2011-0XXX, January, 2011.

${ }^{16}$ Lee, H. C., and Klopfer, G. H., "OVERFLOW Validation for Predicting Plume Impingement of Underexpanded Axisymmetric Jets onto Angled Flat Plates," AIAA Paper No 2011-0XXX, January, 2011.

${ }^{17}$ Kiris, C. C., Housman, J. A., Gusman, M., Schauerhamer, D., Deere, K. A., Elmiligui, A., Abdol-Hamid, K. S., Parlette, E. B., Andrews, M., and Blevins, J. A., "Best Practices for Aero-Database CFD Simulations of Ares V Ascent," AIAA Paper No 2011-0XXX, January, 2011.

${ }^{18}$ Kiris, C. C., Gusman, M., and Housman, J. A., "Best Practices for CFD Simulations of Launch Vehicle Ascent with Plumes" AIAA Paper No 2011-0XXX, January, 2011.

${ }^{19}$ Deere, K. A., Elmiligui, A. A., and Abdol-Hamid, K. S., "CFD Simulations of Heavy Lift Launch Vehicle with Plumes - USM3D Perspective,” AIAA Paper No 2011-0XXX, January, 2011.

${ }^{20}$ Hemsch, M. J., and Walker, E. L., "The Crucial role of Error Correlation for Uncertainty Modeling of CFD-Based Aero Increments," AIAA Paper No 2011-0XXX, January, 2011.

${ }^{21}$ Nance, D. K., and Reed, D. K., "An Assessment of Ares I-X Aeroacoustic Measurements with Comparisons to PreFlight Wind Test Results," AIAA Paper No 2011-0XXX, January, 2011.

${ }^{22}$ Kless, J., and Klopfer, G. H., "Plume-Induced Flow Separation over a Cone-Cylinder Flare Body" AIAA Paper No 2011-0XXX, January, 2011.

${ }^{23}$ Kirchner, R. D., "An Assessment of Ares I-X Upper Stage Compartment Venting with Comparisons Between Flight Test Measurements and Pre-Flight Predictions,” AIAA Paper No 2011-0XXX, January, 2011.

${ }^{24}$ Bartels, R. E., "Flexible Launch Vehicle Stability Analysis Using Rigid CFD with Unsteady Aerodynamic Corrections," AIAA Paper No 2011-0XXX, January, 2011.

${ }^{25}$ Hall, L. H., Eppard, W. M., and Applebaum, M. P., "Debris Transport Modeling Techniques on Launch Vehicle Systems," AIAA Paper No 2011-0XXX, January, 2011.

${ }^{26}$ Lee, H. C., and Klopfer, G. H., "Numerical Investigation of the Flow Angularity Effects of the NASA Langley UPWT on the Ares I DAC1 0.01-Scale Model," AIAA Paper No 2011-0XXX, January, 2011.

${ }^{27}$ Pandya, M. J., Frink, N. T., Abdol-Hamid, K. S., Samareh, J. A., and Parlette, E. B., "Enhancements to TetrUSS for NASA Constellation Program" AIAA Paper No 2011-0XXX, January, 2011.

${ }^{28}$ Hall, L. H., Eppard, W. M., Applebaum, M. P., and Blevins, J. A., "Cartesian Euler Code Application for Launch Vehicle Systems," AIAA Paper No 2011-0XXX, January, 2011.

${ }^{29}$ NASA Explorations Systems Mission Directorate Implementation Plan. (October 2007)

http://www.nasa.gov/directorates/esmd/library/esmd_implementation_plan.html. 